\title{
ANÁLISE DE SUSTENTABILIDADE AMBIENTAL: ESTUDO EM UMA CERÂMICA CATARINENSE
}

\section{ENVIRONMENTAL SUSTAINABILITY ANALYSIS: A STUDY IN CERAMICS CATARINENSE}

\author{
Edilson Citadin Rabelo ${ }^{1}$, Vivian Osmari Uhlmann ${ }^{2}$, Elisete Dahmer Pfitscher ${ }^{3}$, Altair Borgert ${ }^{4}$ \\ Universidade Federal de Santa Catarina - UFSC - Florianópolis - Brasil \\ edilson_rabelo@gmail.com \\ Universidade Federal de Santa Catarina - UFSC - Florianópolis - Brasil \\ vouhlmann@gmail.com \\ Universidade Federal de Santa Catarina - UFSC - Florianópolis - Brasil \\ elisete@cse.ufsc.br \\ Universidade Federal de Santa Catarina - UFSC - Florianópolis - Brasil \\ borgert@cse.ufsc.br
}

\begin{abstract}
Resumo
Este artigo apresenta um estudo referente à constante busca por soluções ligadas a sustentabilidade ambiental, principalmente o consumo e tratamento da água, bem como, o reaproveitamento de resíduos industriais cerâmicos. Busca-se neste sentido, uma relação entre desenvolvimento sustentável e o baixo custo. Este trabalho está focado em o aproveitamento da água e dos rejeitos, visto que, atualmente, alguns empresários perceberam que podem contribuir para a preservação do meio ambiente, utilizando os resíduos da produção. Descobriram uma oportunidade para alavancar seus lucros de maneira significativa, e de certa forma, obter uma nova fonte de renda. Os dados pesquisados foram coletados junto à engenharia de produção de uma indústria cerâmica Catarinense. Trata-se, portanto, de uma pesquisa de caráter exploratóriodescritivo, com abordagem predominantemente qualitativa, cujo objetivo é analisar a sustentabilidade ambiental de uma empresa do ramo cerâmico catarinense, bem como as medidas tomadas por esta empresa para a proteção ambiental e segurança da população em geral, em termos de contaminação da água. A racionalização de consumo de água e resíduos cerâmicos deve ser acrescida por estratégias de reutilização e preservação ambiental, evitando, com isto, impactos ambientais. A análise de sustentabilidade aponta que a Cerâmica Catarina, objeto de estudo, apresenta um índice em torno de 43\%, o qual é considerado como um desempenho ambiental fraco "deficitário", e que pode estar causando danos ao meio ambiente. Como resultado final, conclui-se que a empresa em questão necessita elaborar um planejamento estratégico para sanar este baixo indice de sustentabilidade.
\end{abstract}

Palavras-chave: sustentabilidade ambiental; sistema contábil gerencial ambiental - SICOGEA; cerâmica; resíduos; tratamento da água;

\section{Introdução}

Ensejadas pelo consumismo exacerbado da sociedade contemporânea, as empresas competem 
economicamente e produzem em excesso, visando vender cada vez mais. Surgem, então, novas tecnologias, as quais são implantadas nas indústrias, promovendo o aumento da população em centros urbanos.

Com esta produção desenfreada e a diversidade de bens e serviços consumidos, aumentou a quantidade de resíduos lançados no meio ambiente. Entretanto, muitas indústrias não estavam e ainda não estão preparadas para dar destino correto aos rejeitos.

Nas últimas décadas, agravaram-se consideravelmente os problemas urbanos, por não haver local para armazenar estes resíduos industriais. O alto custo para gerenciar este destino, faz com que as empresas depositem os rejeitos de sua produção em qualquer local, gerando, muitas vezes, problemas para a população com a contaminação ambiental.

A preocupação com o meio ambiente vem crescendo nos últimos tempos, portanto as organizações e sociedade necessitam repensar a sua postura mediante a exploração excessiva dos recursos naturais e o tratamento inadequado de resíduos.

Nesta linha de pensamento, Caubet (2004, p. 152) objetiva que se deve "assegurar à atual e às futuras gerações a necessária disponibilidade de água, em padrões de qualidade adequados aos respectivos usos". Nesse sentido, as empresas em diversos ramos de atividades procuram atender as exigências legais impostas pelo governo, quando se trata de ambientalismo.

Levando em consideração o cenário, surge a seguinte pergunta de pesquisa: qual o índice de sustentabilidade ambiental de uma empresa no ramo cerâmico? Assim, a problemática do reuso da água nas cerâmicas e as questões atinentes à preservação ambiental, bem como, o destino dos resíduos industriais são o foco de interesse para a pesquisa.

Sendo que o objetivo geral do estudo reside em identificar e analisar o grau de sustentabilidade ambiental de uma empresa do ramo cerâmico catarinense, quanto à melhoria da qualidade ambiental, e também, relatar o que a mesma esta implantando a respeito da educação e conscientização ambiental. Especificamente, conhecer uma empresa no ramo cerâmico de Santa Catarina; analisar os procedimentos da produção de cerâmicas; contextualizar os critérios e subcritérios para a análise de sustentabilidade e propor um modelo resumido de gestão ambiental.

Um colaborador da indústria em estudo, através de entrevista, forneceu as informações e dados que auxiliaram na análise do grau de sustentabilidade, porém, por serem informações confidenciais, solicitou anonimato. Achou-se adequado, também, manter o sigilo sobre a identidade da cerâmica e ocultar o nome da referida indústria, que será designada como "CATARINA".

A aplicação de entrevista estruturada, baseada em questionário pré-definido, com a gerência de produção, foi a ferramenta utilizada para levantar os dados e analisar o grau de sustentabilidade ambiental da empresa do ramo cerâmico. Além disso, serviu também para conhecer o tratamento da água e sua reutilização, qual a quantidade consumida e a quantidade não aproveitada, bem como, 
verificar o destino dos resíduos.

Este estudo contribuirá, dentro de suas limitações e proporções, às empresas que desconhecem as exigências legais para a preservação ambiental, evitando, assim, a poluição do meio ambiente.

No meio acadêmico, o estudo pode despertar o interesse para novas análises a respeito da eliminação de resíduos gerados (dejetos químicos) utilizando-se da reciclagem e tratamentos, evitando-se a contaminação do solo e mananciais.

\section{Aspectos metodológicos}

Para responder ao questionamento central da pesquisa, foi utilizada uma lista de verificação, composta de 23 questões, divididas em critérios e sub-critérios, pertencente à primeira fase, da terceira etapa do SICOGEA (Sistema Contábil Gerencial Ambiental), avaliando o que seria considerado como: "A" - Adequado; "D" - Deficitário; "NA" - Não se adapta. Para o cálculo da sustentabilidade ambiental será utilizada a fórmula:

$$
\text { Sustentabilidade }=\frac{\text { Total de questões "A" x } 100}{\mathrm{~N}^{\circ} \text { de questões - "NA" }}
$$

Após o cálculo de sustentabilidade avaliou-se, através da Tabela 1, o grau de sustentabilidade, bem como, o desempenho ambiental da empresa em questão.

Tabela 1 - Avaliação do grau de sustentabilidade e desempenho ambiental

\begin{tabular}{l|l|l}
\hline \multicolumn{1}{c|}{ Resultado } & \multicolumn{1}{c}{ Sustentabilidade } & \multicolumn{1}{c}{ Desempenho: Controle, incentivo, estratégia } \\
\hline Inferior 50\% & Deficitária - "D" & Fraco, pode estar causando danos ao meio ambiente \\
\hline $\begin{array}{l}\text { Entre 51\% e } \\
\mathbf{7 0 \%}\end{array}$ & Regular - "R" & Médio, atende somente a legislação \\
\hline Mais de 71\% & Adequado - "A" & $\begin{array}{l}\text { Alto, valorização ambiental com produção ecológica } \\
\text { e prevenção da poluição. }\end{array}$ \\
\hline
\end{tabular}

Fonte: adaptado de Lerípio (2001) e Miranda e Silva (2002, apud PFITSCHER, 2004, p. 130)

A natureza da pesquisa é aplicada, utilizando-se de abordagem predominantemente qualitativa. Para Richardson (1999, p. 80), “os estudos que empregam uma metodologia qualitativa podem descrever a complexidade de determinado problema, analisar a interação de certas variáveis, compreender e classificar processos dinâmicos vividos por grupos sociais".

Os objetivos traçados são de caráter exploratório, e como fontes de pesquisa foram utilizados artigos, livros, banco de dados do Instituto Brasileiro de Análises Sociais e Econômicas - IBASE, Núcleo de Estudos sobre Meio Ambiente e Contabilidade - NEMAC e outros meios de divulgação que forneceram esclarecimento necessário sobre o tema abordado.

Para analisar o grau de sustentabilidade da cerâmica "Catarina", realizou-se um estudo de caso. Conforme Gil (1991), este procedimento é caracterizado por um estudo exaustivo e profundo 
de um ou poucos objetos, permitindo seu amplo e detalhado conhecimento.

A trajetória metodológica se desenvolve em três etapas, conforme mostra a Figura 1. A primeira etapa inclui o conhecimento da empresa, através da coleta de dados com entrevistas semiestruturadas e estruturadas, compõe "Fazem perguntas" e "Fazem experimentos e coletam dados". Os questionamentos foram direcionados a um colaborador da organização, com formação em administração, responsável pela parte de produção, cuja função demanda conhecimento de todo o processo produtivo.

Figura 1 - Método Científico

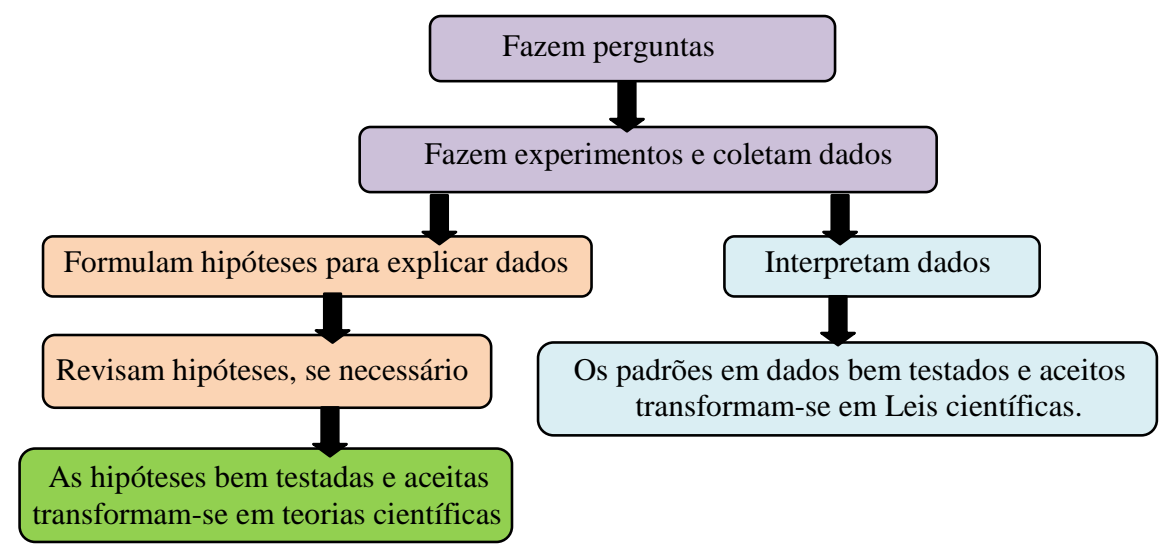

Fonte: Adaptado de Muller Jr. (2007, p.20)

A segunda, etapa inclui a análise ambiental onde "Formulam hipóteses para explicar dados" e "Revisam hipóteses, se necessário". Na sequência, tem-se a terceira etapa com um breve histórico da empresa, com o relato de verificação das atividades e do processo produtivo da Cerâmica Catarina, onde se apresenta as ações "Interpretam dados" e a respeito de gestão ambiental apresentam-se "Os padrões em dados bem testados e aceitos transformam-se em Leis científicas". Nesta etapa discorre-se sobre o reuso da água e também o reuso industrial. Calcula-se no final desta etapa o índice de sustentabilidade da empresa estudada. Neste trabalho não foi utilizada a última ação da Figura 1: "As hipóteses bem testadas e aceitas transformam-se em teorias científicas".

\section{A empresa estudada}

A Cerâmica Catarina foi fundada há algumas décadas e logo se transformou em proprietária de empreendimento moderno, competindo com outros parques fabris de cerâmica no Brasil. O constante aperfeiçoamento tecnológico levou a empresa a iniciar a fabricação da cerâmica monoporosa, uma tendência do mercado.

Situa-se na região sul, onde há uma grande concentração de cerâmicas, todas num raio de aproximadamente $100 \mathrm{~km}$. Esta proximidade formou uma rede ou cluster, configurando um distrito industrial, conforme pode ser observado na Figura 2. 


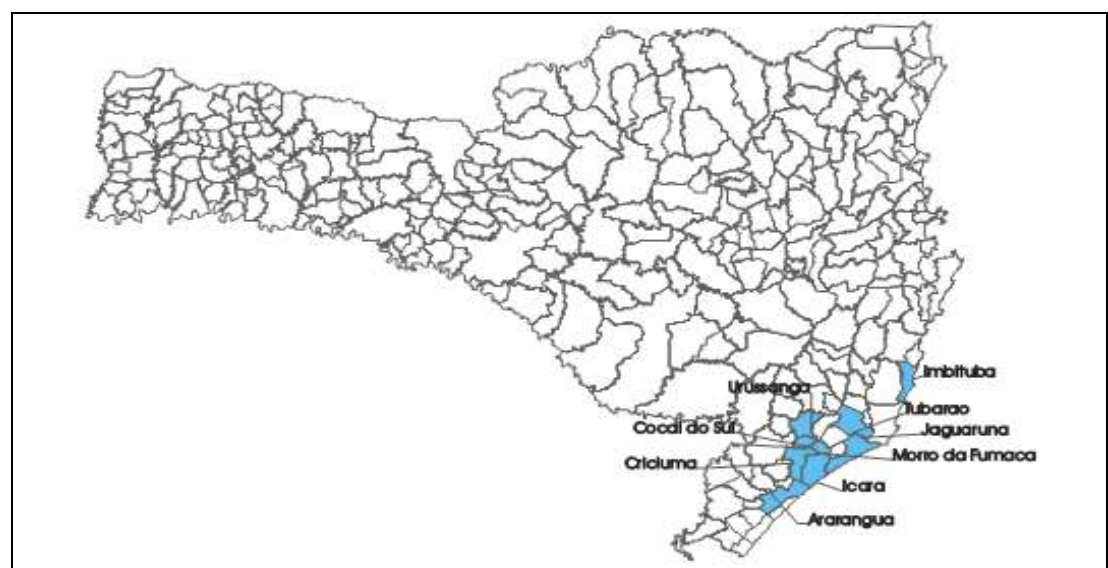

Fonte: Governo do Estado de Santa Catarina

\subsection{Processo produtivo da Cerâmica Catarina}

O processo produtivo inicia com a preparação da massa, passando por várias fases, e termina com a expedição do produto acabado. Para um melhor entendimento das etapas que compõe o processo produtivo da Cerâmica Catarina, segue o Quadro 1.

Quadro 1- Etapas do processo produtivo da Cerâmica Catarina

\begin{tabular}{|c|c|}
\hline ETAPAS & DESCRIÇÃO \\
\hline $\begin{array}{l}\text { Extração da Matéria } \\
\text { Prima }\end{array}$ & $\begin{array}{l}\text { Após a extração e a análise em laboratórios, a matéria-prima extraída de jazidas } \\
\text { da própria empresa ou de terceiros. }\end{array}$ \\
\hline Preparação da Massa & $\begin{array}{l}\text { É seguida uma formulação de massa onde têm várias matérias primas que são } \\
\text { colocadas em moinhos via úmida, obviamente utiliza-se maior quantidade de } \\
\text { água. Após passa por um atomizador que transforma o líquido que é chamado } \\
\text { barbotina em pó, com alta temperatura. }\end{array}$ \\
\hline Prensagem & $\begin{array}{l}\text { Esse pó oriundo da etapa anterior é alimentado em cavidades da prensa e } \\
\text { submetido a uma pressão específica. }\end{array}$ \\
\hline Secagem & $\begin{array}{l}\text { Essa fase tem o intuído de eliminar quase completamente a água que se mantém } \\
\text { nas peças após o processo de prensagem. }\end{array}$ \\
\hline Esmaltação & $\begin{array}{l}\text { Devem-se seguir algumas etapas para garantir a qualidade do produto: pós- } \\
\text { secagem, aplicação de água, engobe, esmalte e decoração serigráfica. }\end{array}$ \\
\hline Queima & O produto segue para o forno e queima da peça. \\
\hline Inspeção & $\begin{array}{l}\text { Na saída de cada forno está instalada a linha de escolha automática. Nela, os } \\
\text { defeitos superficiais são identificados visualmente pelo colaborador, enquanto os } \\
\text { dimensionais são verificados por equipamentos eletrônicos apropriados. }\end{array}$ \\
\hline $\begin{array}{l}\text { Preparação de esmaltes e } \\
\text { tinta }\end{array}$ & $\begin{array}{l}\text { A moagem é feita por via úmida. O moinho é revestido com tijolos de alumina } \\
\text { de alta densidade, bem como os elementos moedores (esferas), proporcionando } \\
\text { alta eficiência na moagem. }\end{array}$ \\
\hline Controle de qualidade & $\begin{array}{l}\text { Tem a função de monitorar todas as fases, desde o controle da matéria-prima até } \\
\text { o produto final. }\end{array}$ \\
\hline Expedição & Realiza o controle do estoque físico de produtos acabados - entrada e saída. \\
\hline
\end{tabular}

Fonte: dados da pesquisa 
Os impactos ambientais causados pelas indústrias cerâmicas são inerentes a praticamente todas as etapas do processo produtivo, desde a extração da matéria-prima (não-renováveis), e também nas etapas de secagem em que é inevitável a geração de resíduos líquidos, bem como, na queima dos revestimentos acontecerá à geração de gases, que prejudicam a sociedade e também a atmosfera.

\section{Gestão ambiental}

As empresas estão percebendo a importância de adotarem medidas para a proteção do meio ambiente.

Ferreira (2003, p. 16) conceitua meio ambiente como "uma área de conhecimento considerada como multidisciplinar. Seu corpo de conhecimento forma-se com base no conhecimento das outras ciências. Pode ser dividido em seis aspectos: 1. ar, 2. água, 3. solo e subsolo, 4. fauna, 5. flora, 6. paisagem".

Muller Jr. (2007) comenta que, o crescimento da população e o consumo exagerado de recursos naturais provocam a poluição do ar, da água e geram desperdícios sólidos, quando não há reaproveitamento necessário para uma sustentabilidade correta. E que, o principal problema não é a urbanização, e sim a falha do ser humano que não cria cidades mais sustentáveis e habitáveis.

Na Love Canal, próximo a Niagara Falls, em Nova York, entre 1942 e 1953, foi cometido um ato criminoso quando armazenaram em barris de aço, dejetos com 200 tipos de compostos químicos e despejados neste canal. Em 1953 o canal foi fechado com argila e terra vegetal, e vendido por US\$1 para o conselho de educação. Em 1959 foram construídas, em torno do canal contaminado, uma escola primária, uma quadra de esportes e 949 casas.

As escavações para a construção de ruas e esgotos atingiram estas áreas, e anos mais tarde crianças foram contaminadas. Entende-se, portanto, que os resíduos tóxicos jamais se desintegram e contaminam para sempre o meio ambiente.

No Brasil esses fatos acontecem, mas em grande maioria não são divulgados, pois há interesse de grandes empresários que não venham à tona. Conforme a Revista Meu Sul (2009), a abertura da mineradora de fosfato, localizada em uma área de preservação permanente - APP, permeada por vales e nascentes de água cristalina, em Anitápolis, na região da Grande Florianópolis dará lugar, provavelmente, a mais uma futura poluidora ambiental. $\mathrm{O}$ que se poderia chamar de sociedade industrial, tornar-se-á sociedade de risco, através do uso inapropriado da terra, criando minas de extração, barragens com altura de até duas vezes a altura do Cristo Redentor e a super exploração do solo.

Qualquer empresa sujeita a problemas ambientais devem obrigatoriamente, se preocupar com o seu planejamento e gestão ambiental. 
Segundo Kraemer (2004), gestão ambiental é o sistema que inclui a estrutura organizacional, atividades de planejamento, responsabilidades, práticas, procedimentos, processos e recursos, para desenvolver, programar, atingir, analisar criticamente e manter a política ambiental. É a forma pela qual a organização se mobiliza interna e externamente, para a conquista da qualidade ambiental desejada. Ela consiste em um conjunto de medidas que visam ter controle sobre o impacto ambiental de uma atividade.

Não se pode esquecer que o sistema de gestão ambiental exige compromisso da administração, proprietários, colaboradores, fornecedores, clientes, prestadores de serviços e qualquer pessoa que tenha envolvimento nas áreas da empresa.

\section{Reuso da água}

Ao diminuir o uso de água de os mananciais hídricos, substituindo a água potável por água que já fora previamente usada, proporcionará uma folga nos reservatórios naturais. O reuso é um método de recuperação de água poluída, garantindo e detectando as propriedades, tais como: pH, turbidez, metais pesados, temperatura, entre outros.

Hoje, os maiores consumidores de água a se considerar são as indústrias, cidades e produtores rurais. Estes, muitas vezes, captam água diretamente de rios, ou lagos e após, jogam os dejetos novamente no rio, poluindo as águas, as quais não poderão mais ser consumidas por homens e animais. Toda esta poluição contamina os lençóis freáticos, comprometendo os aquíferos subterrâneos, considerados reserva natural.

Em a Revista Carta na Escola (2009), o geólogo Everton de Oliveira, especialista em águas subterrâneas, e secretário executivo da Associação Brasileira das águas Subterrâneas (ABAS), diz que zelar pelos aquíferos é uma questão vital, e que, "caso aumente a concentração de compostos indesejáveis, toda a água ficará imprópria para o consumo sem o tratamento específico”. Diz ainda que as águas subterrâneas são reservatórios que se movimentam muito lentamente, formados pelas águas das chuvas, que se infiltram no solo e chegam a ter muitas vezes mil anos de idade. Grande parte dos rios do país é abastecida por estas águas. Sobre a escassez das águas, o geólogo discorre que o termo escasso é muito relativo, pois a quantidade de água no planeta é fixa, não está deixando de existir. O que realmente preocupa é o aumento na concentração de compostos indesejáveis, os quais deixam a água imprópria para o consumo humano.

Uriel Duarte, professor de recursos hídricos e geologia ambiental da USP, na revista Carta na Escola (2009), diz que o planeta Terra tem $65 \%$ de sua superfície coberta por água, deste percentual, 97\% são salgadas (mares e oceanos) e apenas 3\% são doces. Da água doce, própria para consumo humano, 96\% é proveniente de águas subterarâneas, que garantem a sobrevivência de parte significativa da população mundial. 


\subsection{Reuso industrial}

Em quase todos os processos de produção de pisos e azulejos, um dos principais insumos empregados é a água. A escolha da localização de instalação de uma indústria cerâmica faz-se em relação à disponibilidade de água, pois os custos de produção estão a ela diretamente relacionados.

Anteriormente, as indústrias cerâmicas eram implantadas distante da sociedade, mas com o passar dos tempos e crescimento da população, o contato próximo com a cerâmica tornou-se inevitável.

É grande, portanto, o risco de degradação ambiental, e as medidas de preservação deverão ser colocadas em prática, porque as cerâmicas são consideradas grandes poluidoras dos mananciais hídricos. Esta contaminação coloca em risco não só o meio ambiente, mas também a sobrevivência humana.

Vaitsman (2006, p. 67), considera que a contaminação:

[...] em represas ou outros tipos de reservatórios, o fator antrópico pode ocasionar produção excessiva de microorganismos tóxicos ao homem. Do mesmo modo, a presença de metais e de compostos orgânicos em concentrações superiores às estabelecidas pela legislação também provoca danos à saúde dos seres vivos. A água bruta, captada diretamente de mananciais e acumulada em represas, ou bombeada diretamente de poços artesianos, deve receber tratamento químico e/ou desinfectada com cloro, para eliminar microorganismos patogênicos, antes de ser distribuída para consumo pela população em condições de potabilidade (VAITSMAN, 2006, p.67)

É importante salientar que, a água, no processo industrial cerâmico, passa por várias etapas, deixando-a, após várias limpezas e misturas, com partículas metálicas consideradas metais pesados, tais como o chumbo e mercúrio, que são facilmente encontrados nos efluentes industriais, e quando lançados sem o respectivo tratamento adequado, causam impactos ambientais negativos.

A Resolução no 357 de 17 de março de 2005 do CONAMA (Conselho Nacional do Meio Ambiente), estabelece condições e padrões de lançamento de efluentes, em seu art. 24 e determina que "os efluentes de qualquer fonte poluidora somente poderão ser lançados, direta ou indiretamente, nos corpos de água, após o devido tratamento e desde que obedeçam às condições, padrões e exigências dispostos nesta Resolução e em outras normas aplicáveis".

Já, no inciso II, do parágrafo único do referido artigo, a Resolução determina que "o órgão ambiental competente possa a qualquer momento exigir a melhor tecnologia disponível para o tratamento dos efluentes, compatível com as condições do respectivo curso de água superficial, mediante fundamentação técnica".

Para fazer o reuso da água é preciso selecionar um apropriado sistema de tratamento e verificar quais as técnicas existentes, a viabilidade econômica do procedimento, tratando e monitorando a água.

É preocupante, entretanto, saber, através de informações do colaborador, que o órgão 
responsável pela expedição da autorização ambiental e vistorias de agressão ao meio ambiente FATMA (Fundação do Meio Ambiente - do Estado de Santa Catarina) fornece liberação para funcionamento, mas fiscaliza somente em caso de denunciais.

A Cerâmica Catarina informa em seu site e meios de comunicação, que se preocupa com o meio ambiente. Logo, com o intuito de responder a questão problema, que busca identificar o índice de sustentabilidade ambiental de uma empresa no ramo cerâmico, utilizou-se o método SICOGEA, para a avaliação de sustentabilidade e desempenho ambiental da cerâmica em questão.

\section{Análise de sustentabilidade}

Muitas empresas têm dificuldade, ou até mesmo, desconhecem a existência de metodologias de cálculo do grau de sustentabilidade de uma empresa, para saber se ela está agredindo ou não o meio ambiente. $\mathrm{O}$ trabalho em questão foi desenvolvido em uma indústria cerâmica catarinense, no qual os dados e exemplos objetivam-se a demonstrar, através de uma fórmula do SICOGEA (Sistema Contábil Gerencial Ambiental), qual o grau de sustentabilidade, bem como, o desempenho ambiental da empresa em análise.

Para responder a questão central deste estudo, aplicou-se uma lista de verificação, contendo 23 questões, avaliando cada resposta obtida como: "A" - Adequada ou "D" - Deficitária ou "NA" Não se adapta.

No Quadro 2 demonstram-se as perguntas, assim como o respectivo enquadramento das respostas, direcionadas ao encarregado da produção na Cerâmica Catarina, que tem experiência de aproximadamente seis anos no ramo cerâmico.

Quadro 2 - Lista de verificação

\begin{tabular}{|l|c|c|c|}
\hline CRITÉRIO 2 - ECOEFICIÊNCIA DO PROCESSO PRODUTIVO & SIM & NÃO & NA \\
\hline 1 - Produção da cerâmica em m²? & A & & \\
\hline 2 - Qual é o consumo de água na Cerâmica em que trabalha? & A & & \\
\hline 3 - A água provém de lago na empresa? & A & & \\
\hline 4 - Para quais processos é utilizada esta água? & A & & \\
\hline $\begin{array}{l}5 \text { - Quais são os componentes químicos incluídos na água para o } \\
\text { tratamento e reaproveitamento? }\end{array}$ & A & & \\
\hline 6 - Quanto da água é reaproveitada? & A & & \\
\hline 7 - Quanto de água é evaporada no processo? & & D & \\
\hline 8 - Onde é armazenada a água reaproveitada? & A & & \\
\hline $\begin{array}{l}\text { 9 - Existe um planejamento estratégico para a empresa no tratamento da } \\
\text { água? }\end{array}$ & & D & \\
\hline $\begin{array}{l}10 \text { - O que pode ocorrer quando o processo de recuperação da água não é } \\
\text { completo? }\end{array}$ & & D & \\
\hline 11 - Existe algum descarte, material não utilizado? Qual o destino? & A & & \\
\hline $\begin{array}{l}12 \text { - A empresa conhece os procedimentos realizados pela empresa } \\
\text { terceirizada? }\end{array}$ & & D & \\
\hline $\begin{array}{l}13 \text { - Como é realizado o processo de controle de quantidade de água? } \\
\text { A }\end{array}$ & A & & \\
\hline
\end{tabular}




\begin{tabular}{|l|c|c|c|}
\hline 14 - Quais as modificação sofridas pela água com o reaproveitamento? & D & \\
\hline 15 - Já aconteceu contaminação nos rios da cidade? & D & \\
\hline 16 - Existe fiscalização sobre o rejeito da água na cerâmica? & D & \\
\hline 17 - A empresa já sofreu notificação por poluir o meio ambiente? & & D & \\
\hline 18 - Qual a providência que tomou para melhorar o processo? & A & & \\
\hline 19 - As ações destas providências auxiliaram no processo de anomalias? & & D & \\
\hline 20 - Qual a expectativa de vida útil do manancial? & D & \\
\hline $\begin{array}{l}21 \text { - O manancial e a exaustão são lançados na contabilidade no ativo } \\
\text { imobilizado? }\end{array}$ & & D & \\
\hline 22 - O balanço da empresa demonstra o aspecto ambiental? & & \\
\hline 23 - Existe uma forma de certificação ambiental? & & D & \\
\hline
\end{tabular}

Fonte: Dados da pesquisa

Em análise às respostas apresentadas no Quadro 2, verifica-se que a produção mensal da fábrica Catarina é de $800.000 \mathrm{~m}^{2}$ e o consumo de água chega a $20.000 \mathrm{~m}^{3}$ por hora. Esta água utilizada provém de um lago, situado nos fundos da empresa, de propriedade da organização.

A empresa utiliza a água para os processos de produção, desde a esmaltação, "retífica", ou seja, o corte da cerâmica que requer muita água. A água também é utilizada para lavar as telas, moinhos e silos. São usados produtos químicos para decantação (separação da água e lama), e após um equilibrador de PH para o tratamento e reaproveitamento. Este tratamento proporciona um retorno e reaproveitamento da água em torno de $70 \%$.

Porém, verifica-se que a água no processo de produção se perde em $30 \%$ por evaporação, porque é empregada na refrigeração das prensas. É o contato da água fria com peças quentes que causa essa evaporação.

A água reaproveitada é armazenada em um reservatório subterrâneo, de onde é bombeada, novamente, para a fábrica. É um reservatório de concreto revestido com tinta epóxi, para evitar vazamentos.

A empresa se preocupa em tratar quimicamente a água utilizada e reaproveitada na produção, para não prejudicar o meio ambiente, entretanto, o correto seria a instalação de canos de inox, o qual evitaria a oxidação dos canos e contaminação do solo.

Quando o processo de recuperação da água não é completo, a empresa faz a captação do lago, localizado na própria organização. Sendo que esta captação torna-se necessária, principalmente, quando há os $30 \%$ de perdas da própria evaporação do processo.

Uma empresa terceirizada recolhe os detritos não utilizados na produção, ou seja, o descarte do material não utilizado. Segundo o colaborador entrevistado, a organização desconhece os procedimentos realizados pela empresa terceirizada, que recolhe os descartes, e qual o destino que é dado aos mesmos.

A Cerâmica Catarina controla a quantidade da água através de hidrômetros, que medem o consumo de água utilizada na produção. 
Quando a água é reaproveitada, sofre transformações perdendo todas as propriedades fisioquímicas, ficando mais ácida, com turbidez acentuada (tipo leitosa).

Constatou-se, também, que houve rompimento de canos na produção, e os resíduos e águas contaminadas foram jogadas diretamente em um córrego que passa ao lado da empresa.

A FATMA, que é o órgão responsável pela liberação do certificado ambiental, foi fiscalizar a empresa em estudo. Isso comprova que a fiscalização por parte desse órgão só acontece em casos de denúncias.

Vale lembrar que a empresa já havia sofrido notificação por poluir o meio ambiente, quando houve o rompimento dos canos e contaminação do córrego.

Após a empresa receber notificação por poluir o meio ambiente, substituiu as tubulações com revestimentos epóxi, e passou a realizar análises diárias de concentração da água, a fim de obter divergências em seus resultados, para detectar anomalias (vazamentos, qualidade de água no reprocesso).

Providências foram tomadas para solucionar estas anomalias, porém o procedimento correto, segundo o colaborador da empresa, seria o investimento em canos de inox, o que garantiria total segurança evitando vazamentos futuros. O principal entrave para a realização destes investimentos são os altos custos.

Cabe mencionar que a empresa não se preocupa com a expectativa de vida útil do manancial, de onde utiliza a água para a produção.

O colaborador informou que o manancial e a sua exaustão não estão registrados no ativo não circulante da empresa, e que desconhecia a existência e a legalidade deste item.

Relatou, ainda, que a empresa não demonstra os aspectos ambientais em seu Balanço Patrimonial e que não possui certificação ambiental, mesmo conhecendo a norma ISO 14.000.

Analisando estas informações, verifica-se pelo Quadro 2, que os itens 1 a 6, 8, 11, 13 e 18, são considerados “Adequados”. Já os demais itens são considerados como "Deficitários".

Assim, torna-se necessário apresentar o cálculo de sustentabilidade, uma vez que o objetivo deste estudo é analisar o coeficiente encontrado e verificar se a cerâmica Catarina está ou não agredindo o meio ambiente, colocando em risco a população em geral.

Para o cálculo da sustentabilidade ambiental foi utilizada a fórmula (Total de questões " $\mathrm{A}$ " $\mathrm{x}$ 100/ total de questões - questões "NA”), já citada no capítulo metodológico.

Quanto à análise de sustentabilidade, percebeu-se a ocorrência de dez questões classificadas como adequadas, contra zero de questões enquadradas como não adequadas à realidade da Cerâmica Catarina, de um total de 23 questões, o que representa:

$(10 * 100) /(23-0)=43,48 \%$ 
Perfaz-se, assim, um índice de sustentabilidade de 43,48\%, o que, segundo a Tabela 1 , representa um desempenho ambiental deficitário, considerado fraco. De acordo com o método de avaliação da sustentabilidade adotado nesta pesquisa, pode-se dizer que a empresa está causando danos ao meio ambiente.

Diante disso, questiona-se como a Cerâmica Catarina conseguiu, durante estes dez anos de operação, manter a liberação ambiental da Fundação do Meio Ambiente (FATMA).

Concluiu-se que a empresa necessita inovar e implantar tecnologias ou processos que detectem instantaneamente qualquer anomalia que agrida o meio ambiente, e que os dirigentes da organização busquem um nível de sustentabilidade favorável.

\section{Conclusões e sugestões para futuros trabalhos}

Com a globalização, a competição do setor cerâmico de revestimento em Santa Catarina ampliou-se, provocando uma reestruturação industrial. Para as empresas alcançarem patamares mais elevados de produção, investem em novas tecnologias e melhoria na qualidade dos produtos e dos processos industriais. A concorrência, entretanto, força as cerâmicas a produzirem mais, pois há excesso de oferta e consumo. Por ser esse um grande desafio e para atender o público consumidor, as indústrias produzem em larga escala e provocam danos ao meio ambiente com o excesso de resíduos da produção.

Neste contexto, é imprescindível que as organizações repensem sua postura ecologicamente correta, não só visando atender a legislação, como exemplo da Cerâmica Catarina, mas também a responsabilidade socioambiental. Esta postura ecologicamente correta vem conquistando espaços nas empresas, as quais pretendem serem valorizadas e respeitadas por seus clientes, consumidores e sociedade.

Neste mundo contemporâneo e consumista, as empresas aos poucos estão se conscientizando da necessidade de preservar o nosso Planeta, e escolhem fornecedores que respeitem o meio ambiente.

Todavia, as organizações necessitam conquistar um desenvolvimento sustentável, e gerar lucros protegendo o meio ambiente. Assim, devem seguir a todos os parâmetros exigidos pela legislação federal, bem como, conscientizar-se de que o futuro do planeta depende de ações ecologicamente corretas.

O presente trabalho identificou e analisou o índice de sustentabilidade ambiental de uma empresa do ramo cerâmico, nesta pesquisa denominada Cerâmica Catarina. E, através da avaliação da sustentabilidade e desempenho ambiental, concluiu-se que a indústria necessita adotar um sistema de gestão ambiental, que repare os pontos de maior prioridade observados na análise das respostas da lista de verificação aplicada, considerados deficitários. Este sistema de gestão 
ambiental atribuirá maior comprometimento para a entidade, e tranquilidade para a sociedade.

A questão problema norteadora da pesquisa foi: qual o índice de sustentabilidade ambiental de uma empresa no ramo cerâmico?

A análise de sustentabilidade da Cerâmica Catarina fez-se com base nas informações obtidas através de entrevista semi-estruturada a um colaborador da empresa, encarregado da produção. Constatou-se, então, que a organização não possui um sistema de gestão ambiental.

Os resultados auferidos da lista de verificação mostraram que o índice de sustentabilidade da Cerâmica Catarina, em se tratando do critério 2 - (ecoeficiência do processo produtivo) é de 43,48\%, considerado "deficitário". Entende-se, portanto, que a referida empresa pode estar causando danos ao meio ambiente.

É fundamental que empresa invista em um profissional capacitado na área contábil, que tenha conhecimento sobre a contabilidade ambiental, conheça também técnicas de tratamento e reaproveitamento da água utilizada na produção, bem como, entenda que os mananciais devam ser registrados na contabilidade e depreciados ao longo dos anos. Com a contabilidade ambiental, a empresa poderá prestar informações à sociedade sobre os cuidados e benefícios ambientais prestados, divulgando notas explicativas em seus balanços anuais.

Verificou-se que a empresa em estudo foi multada em virtude de um vazamento de resíduos sólidos que contaminou o lago próximo a entidade. Não houve preocupação em avaliar com exatidão qual foi o grau de contaminação do meio ambiente. Houve preocupação unicamente em sanar a contaminação e continuar o processo normal de fabricação.

Torna-se importante a continuidade e a realização de novos estudos sobre o setor cerâmico catarinense, devido a sua grandeza em termos de produção, tanto regional como nacional. Sabe-se que $30 \%$ da produção nacional de revestimentos cerâmicos estão localizados no Estado de Santa Catarina.

Com isso, sugere-se para futuros trabalho a aplicação da metodologia do SICOGEA nas demais empresas do ramos cerâmico situadas na região Sul, bem como a aplicação das demais etapas deste sistema.

\section{Abstract}

This article presents a study on the constant search for solutions related to environmental sustainability, especially consumption and water treatment, as well as recycling of waste industrial ceramics. Search in this sense, the relationship between sustainable development and low cost. This work focuses on the use of water and waste, as now, some entrepreneurs realized that they can help preserve the environment by using waste production. They found an opportunity to boost their profits significantly, and somehow get a new source of income. The research data were collected in a production engineering ceramics industry of Santa Catarina. It is therefore a search for exploratory and descriptive, with a predominantly qualitative approach, aiming to examine the environmental sustainability of a company of ceramic Santa Catarina, and the measures taken by 
this company for environmental protection and safety of general population in terms of water contamination. The rationalization of water consumption and waste ceramic should be increased by strategies to reuse and environmental preservation, avoiding, thus, environmental impacts. The sustainability analysis indicates that the Ceramic Catherine, the object of study, presents an index of around $43 \%$, which is regarded as a poor environmental performance "deficit" and that may be causing harm to the environment. As a final result, we conclude that the company in question needs to develop a strategic plan to address this low level of sustainability.

Keywords: environmental sustainability; environmental management accounting system SICOGEA; ceramics; waste; water treatment.

\section{Referências}

CINTRA, L. A. Tesouro líquido: o desperdício do que não se vê. Revista Carta na Escola, Editora Confiança. São Paulo: 2009.

CONSELHO NACIONAL DO MEIO AMBIENTE. (2005). Resolução n. 357, de 17/03/05. Disponível em: <http://www.mma.gov.br/port/conama/res/res05/res35705.pdf>. Acesso em: 02 Jan. 2009.

GIL, A. C. Como elaborar projetos de pesquisas. 3. ed. São Paulo: Atlas,1991.

KRAEMER, M. E. P.; TINOCO, J. E. P. Contabilidade e gestão ambiental. São Paulo: Atlas, 2004.

MILLER JR., G. T. Ciência ambiental. 11. ed. São Paulo: Cengage, 2007.

PFITSCHER, E. D. Gestão e sustentabilidade da contabilidade e controladoria ambiental: estudo de caso na cadeia produtiva de arroz ecológico. 2004. 252.f. Tese - Universidade Federal de Santa Catarina - UFSC. Florianópolis, 2004.

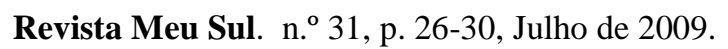

RICHARDSON, R. J. Pesquisa social: métodos e técnicas. 3.ed. São Paulo: Atlas,1999.

ROSA, F. S. da et al.. Responsabilidade sócio-ambiental analisada em uma rede de supermercados com auxilio do SICOGEA. Artigo - UFSC - Florianópolis. 2008.

VAITSMAN, E. P.; VAITSMAN, D. S. Química \& meio ambiente: ensino contextualizado. Rio de Janeiro: Interciência, 2006.

\section{Dados dos autores:}

Nome completo: Edilson Citadin Rabelo

Filiação institucional: Professor da Faculdade de Capivari (FUCAP)

Departamento:

Função ou cargo ocupado: Mestrando do Programa de Pós-Graduação em Contabilidade da UFSC.

Endereço completo para correspondência (bairro, cidade, estado, país e CEP): AVENIDA NAÇÕES UNIDAS, 500 - SANTO ANDRÉ - 88745-000 - Capivari de Baixo, SC - Brasil

Telefones para contato: (48) 36236000

e-mail: edilson.rabelo@gmail.com 
Nome completo: Vivian Osmari Uhlmann

Filiação institucional: Universidade Federal de Santa Catarina - UFSC

Função ou cargo ocupado: Mestre em Contabilidade pela Universidade Federal de Santa Catarina (UFSC) e Bacharel em Ciências Contábeis pela Universidade Federal de Santa Maria (UFSM)

Endereço completo para correspondência (bairro, cidade, estado, país e CEP): Rua Rodolfo Manoel Bento, 160, apto. 305, Bairro Carvoeira, CEP: 88040-490, Florianópolis - SC.

Telefones para contato: (48) 91090447

e-mail:vouhlmann@gmail.com

Nome completo: Elisete Dahmer Pfitscher

Filiação institucional: Universidade Federal de Santa Catarina - UFSC

Função ou cargo ocupado: Docente do Programa de Pós-Graduação em Contabilidade

Doutora em Engenharia da Produção pela UFSC

Endereço completo para correspondência (bairro, cidade, estado, país e CEP):

Campus Universitário - Trindade - Caixa Postal 476 CEP. 88040-900 - Florianópolis, SC - Brasil

Telefones para contato: (048)3364 2028

e-mail: elisete@cse.ufsc.br

\section{Nome completo: Altair Borgert}

Filiação institucional: Universidade Federal de Santa Catarina - UFSC

Função ou cargo ocupado: Docente do Programa de Pós-Graduação em Contabilidade - UFSC

Doutor em Engenharia da Produção pela UFSC

Endereço completo para correspondência (bairro, cidade, estado, país e CEP):

Campus Universitário - Trindade - Caixa Postal 476 CEP. 88040-900 - Florianópolis, SC - Brasil

Telefones para contato: (048)3364 2028

e-mail: borgert@cse.ufsc.br

Enviado em:26/03/2011

Aprovado em: 20/12/2011 